\title{
Viabilidade de Sementes de Ocotea puberula (Rich.) Ness ao Longo do Armazenamento
}

\author{
Dalciana Vicente ${ }^{1}$, Luciana Magda de Oliveira ${ }^{1}$, Olívia Alvina Oliveira Tonetti², \\ Adriano Alves Silva ${ }^{2}$, Patrícia Paloma Liesch ${ }^{1}$, Mara Luana Engel $^{1}$ \\ ${ }^{1}$ Universidade do Estado de Santa Catarina - UDESC, Lages/SC, Brasil \\ ${ }^{2}$ Universidade Federal de Lavras - UFLA, Lavras/MG, Brasil
}

\begin{abstract}
RESUMO
Objetivou-se verificar a viabilidade de sementes e a integridade do DNA de Ocotea puberula durante armazenamento, com e sem o fruto. Sementes de cinco lotes foram armazenadas com e sem fruto, em câmara fria e seca (UR $40 \% \pm 3 \%$ e temp. $10{ }^{\circ} \mathrm{C} \pm 2{ }^{\circ} \mathrm{C}$ ), pelos períodos de 0, 3, 6 e 9 meses. A cada período foram determinados o teor de água, germinação (\%), tetrazólio (\%) e integridade do DNA. O teste de germinação foi realizado em papel germitest, em germinador a $30{ }^{\circ} \mathrm{C}$, sob luz constante. O teste de tetrazólio foi realizado com solução na concentração de $0,5 \%$, pelo período de 1 hora. A integridade do DNA das sementes foi analisada em gel de agarose e a concentração de DNA mensurada com espectrômetro NanoDrop ${ }^{\circledR}$. Foi verificado que somente sementes armazenadas sem o fruto mantiveram sua germinação por até três meses. Após esse período, a germinação das sementes foi reduzindo-se gradativamente, sendo nula aos 9 meses. Na análise da integridade do DNA de sementes foi possível visualizar sua degradação ao longo do armazenamento. Sementes de O. puberula, com ou sem fruto, armazenadas em sacos de papel kraft reduzem sua viabilidade e integridade de DNA após 3 meses de armazenamento em câmara fria e seca.
\end{abstract}

Palavras-chave: germinação, sementes recalcitrantes, canela-guaicá.

\section{Viability of Ocotea puberula (Rich.) Ness Seeds During Storage}

\begin{abstract}
This study aimed to verify the DNA integrity and viability of Ocotea puberula seeds, with and without fruit, during storage. Seeds of five lots were stored, with and without fruit, in cold and dry chamber $\left(40 \% \pm 3 \% \mathrm{RH} ; 10^{\circ} \mathrm{C} \pm 2{ }^{\circ} \mathrm{C}\right)$ for $0,3,6$, and 9 months. The following attributes were determined at each period: water content, germination potential (\%), tetrazolium (\%), and DNA integrity. Seed germination was conducted in germitest paper, in germinator at $30^{\circ} \mathrm{C}$ under constant light. The tetrazolium test was performed in $0.5 \%$ solution for 1 hour. The DNA integrity of seeds was analyzed in agarose gel and DNA concentration was measured using a NanoDrop ${ }^{\circledR}$ spectrometer. The results showed that only seeds without fruit maintained germination for three months; after this period, the germination of seeds reduced gradually, becoming null after nine months. Seed degradation during storage was observed in the DNA integrity analysis. Ocotea puberula seeds, with or without fruit, stored in Kraft paper bags in cold and dry chamber had their viability and DNA integrity reduced after three months.
\end{abstract}

Keywords: germination, recalcitrant seeds, canela-guaicá. 


\section{INTRODUÇÃO}

Conhecida popularmente por canela-guaicá, a Ocotea puberula (Rich.) Ness (Lauraceae) possui ampla distribuição geográfica na América do Sul, com importância medicinal, para a recomposição de áreas degradadas e plantios comerciais (Zangaro et al., 2003; Montagnini et al., 2006; Montrucchio et al., 2012). A produção de mudas dessa espécie é feita via seminal e, muitas vezes, é limitada devido à pouca disponibilidade de sementes.

$\mathrm{O}$ armazenamento tem por objetivo conservar as sementes, preservando suas qualidades físicas, fisiológicas e sanitárias. Além disso, tem a função de manter uma disponibilidade contínua de sementes viáveis, imprescindíveis aos programas florestais e à conservação em bancos de germoplasma (Floriano, 2014).

A viabilidade das sementes, no armazenamento, pode ser influenciada pela espécie, qualidade inicial, umidade das sementes, umidade relativa e temperatura do ambiente, fungos e insetos, tipo de embalagem e duração do período de armazenamento (Tekrony et al., 1987; Carvalho \& Nakagawa, 2012).

A principal estratégia para conservação de sementes durante o armazenamento é a redução do seu metabolismo, através da remoção da água e da redução da temperatura. Contudo, nem todas as sementes toleram ser armazenadas a baixas temperatura e umidade (Mello, 2008), perdendo sua qualidade rapidamente. Sementes ortodoxas podem ser secas a graus de umidade baixos e com isso podem ser armazenadas por longos períodos de tempo, enquanto que as recalcitrantes são dispersas com conteúdos elevados de água e não podem perder grande porcentagem de água ou serem armazenadas por períodos que excedam algumas semanas ou meses, o que representa um desafio para sua conservação $e x$ situ (Marcos, 2005).

Hong \& Ellis (1996), ao estudarem o comportamento de sementes de espécies de Lauraceae no armazenamento, verificaram que, dentre 34 espécies, $74 \%$ apresentavam indícios de recalcitrância. Esses resultados também foram verificados em sementes de: Nectandra grandiflora, N. lanceolata, N. oppositifolia, Ocotea corymbosa e O. pulchella (Carvalho et al., 2008); O. porosa, O. catharinensis e O. odorifera (Moritz et al., 2009); e Cinnamomum zeylanicum (Silva et al., 2012).
A perda da viabilidade das sementes está fortemente correlacionada com alterações na atividade respiratória, acúmulo de substâncias tóxicas, danos à integridade do DNA e à perda gradativa da integridade do sistema de membranas, acarretando a liberação de solutos celulares, importantes para o funcionamento da célula (Marcos, 2005).

As sementes são compostas por muitas substâncias de reserva (carboidratos, proteínas, lipídios), em proporções que variam para cada espécie (Santos et al., 2004). Sementes com baixa viabilidade perdem a eficiência na sintetização de RNA e as lesões ao DNA aumentam as chances de um processo de transcrição da mensagem genética defeituoso ser gerado. Tais danos acumulam-se mais rapidamente em sementes úmidas que nas secas e estão relacionados ao envelhecimento e à perda da viabilidade das sementes (Marcos, 2005).

Sementes de Ocotea puberula têm comportamento recalcitrante (Mori et al., 2012), perdendo totalmente a viabilidade em ambiente não controlado em três meses, sendo difícil a sua conservação (Eibl et al., 1994). Randi (1982) recomenda que as sementes dessa espécie sejam armazenadas com os frutos, pois eles possuem substâncias inibidoras da germinação, garantindo, desse modo, a dormência.

Trabalhos científicos que estudam o armazenamento de sementes em seu fruto como alternativa para a conservação de sementes sensíveis ao dessecamento, como as de Caesalpinia leiostachya (Biruel et al., 2007) e as de Crambe abyssinica (Costa et al., 2012), são escassos, mas com efeito positivo.

Objetivou-se com este trabalho determinar a viabilidade de sementes e a integridade do DNA de O. puberula durante armazenamento com e sem fruto, em condições de câmara fria e seca.

\section{MATERIAL E MÉTODOS}

Os frutos de Ocotea puberula foram coletados no estado de Santa Catarina, nos municípios de Joaçaba, Fraiburgo, Curitibanos, Ponte Alta e Brunópolis, estabelecendo-se 5 lotes distintos (Tabela 1).

Foram colhidos frutos com coloração preto-azulada, considerados maduros, de 5 matrizes em cada município, com exceção de Fraiburgo, onde foram encontradas apenas 2 matrizes. Após a coleta, os frutos foram acondicionados em sacos plásticos. 
Tabela 1. Dados geográficos e climáticos dos locais de coleta de frutos de Ocotea puberula.

Table 1. Geographical and climatic data from local to collect of Ocotea puberula fruits.

\begin{tabular}{ccccccl} 
Lote & Município & Latitude & Longitude & Altitude & $\begin{array}{c}\text { Temp. } \\
\text { média }\end{array}$ & Clima \\
\hline 1 & Joaçaba & $27^{\circ} 10^{\prime} 41^{\prime \prime} \mathrm{S}$ & $51^{\circ} 30^{\prime} 17^{\prime \prime} \mathrm{O}$ & $522 \mathrm{~m}$ & $18^{\circ} \mathrm{C}$ & Subtropical úmido \\
\hline 2 & Fraiburgo & $27^{\circ} 03^{\prime} 20^{\prime \prime} \mathrm{S}$ & $50^{\circ} 03^{\prime} 34^{\prime \prime} \mathrm{O}$ & $1048 \mathrm{~m}$ & $16,1^{\circ} \mathrm{C}$ & Subtropical úmido \\
\hline 3 & Curitibanos & $27^{\circ} 16^{\prime} 44^{\prime \prime} \mathrm{S}$ & $50^{\circ} 34^{\prime} 57^{\prime \prime} \mathrm{O}$ & $987 \mathrm{~m}$ & $15,2^{\circ} \mathrm{C}$ & Subtropical úmido \\
\hline 4 & Ponte Alta & $27^{\circ} 29^{\prime} 03^{\prime \prime} \mathrm{S}$ & $50^{\circ} 22^{\prime} 49^{\prime \prime} \mathrm{O}$ & $856 \mathrm{~m}$ & $16^{\circ} \mathrm{C}$ & Subtropical úmido \\
\hline 5 & Brunópolis & $27^{\circ} 18^{\prime} 21^{\prime \prime} \mathrm{S}$ & $50^{\circ} 52^{\prime} 06^{\prime \prime} \mathrm{O}$ & $843 \mathrm{~m}$ & $19^{\circ} \mathrm{C}$ & Subtropical úmido \\
\hline
\end{tabular}

Fonte: Santa Catarina (2014), Köppen \& Geiger (1936).

Para as sementes armazenadas sem o fruto, a remoção da polpa foi feita manualmente, com o auxílio de peneiras e água corrente, no mesmo dia da coleta. O excesso de água foi retirado com papel toalha. As sementes foram submetidas aos tratamentos logo após a colheita (com fruto) e extração (sem fruto).

Para o armazenamento, amostras de 180 sementes de cada lote, com e sem fruto, foram colocadas em sacos de papel do tipo kraft e armazenadas em câmara fria e seca (UR $40 \% \pm 3 \%$; temp. $10{ }^{\circ} \mathrm{C} \pm 2{ }^{\circ} \mathrm{C}$ ). Aos 0, 3, 6 e 9 meses de armazenamento foram retiradas amostras para avaliação da umidade, viabilidade (testes de germinação e tetrazólio) e integridade do DNA. $\mathrm{O}$ experimento foi realizado em esquema fatorial de $2 \times 4 \times 5$, sendo sementes com ou sem fruto, em 4 períodos de armazenamento, de 5 lotes.

Para as avaliações, as sementes do tratamento com fruto foram extraídas conforme citado. A determinação do teor de água foi realizada pelo método de estufa à temperatura de $103{ }^{\circ} \mathrm{C} \pm 2{ }^{\circ} \mathrm{C}$ durante $24 \mathrm{~h}$. Foram feitas 2 repetições para cada lote, contendo 4 gramas por repetição. Os resultados foram expressos em porcentagem com base no peso úmido das sementes, conforme as Regras para Análise de Sementes (Brasil, 2009).

Para o teste de germinação, as sementes foram distribuídas em papel germitest, previamente umedecido a duas vezes o peso do papel (Brasil, 2009) e colocadas em germinador tipo Mangerdorffii regulado a $30^{\circ} \mathrm{C}$, sob luz constante (Bilia et al., 1998). Para cada lote, foram utilizadas 4 repetições de 20 sementes sem tegumentos (Vicente, 2014), totalizando 80 sementes. A avaliação foi realizada após 36 dias da montagem do teste, com a estabilização do estande, sendo consideradas germinadas sementes que deram origem a plântula normal.

Para o teste de tetrazólio, 60 sementes, divididas em 4 repetições, foram embebidas em água pelo período de 16 horas, seccionadas longitudinalmente, através do centro do eixo embrionário, com auxílio de um bisturi, e imersas na solução de 2,3,5 trifenil cloreto de tetrazólio ( $\mathrm{pH} 6,5$ a 7,0), na concentração de $0,5 \%$, pelo período de 1 hora (Kalil et al., 2008). Para auxiliar na visualização de todos os detalhes das sementes, foram utilizadas lupas de mesa com lâmpada fluorescente. Os critérios de análise foram: 1 - semente viável (coloração avermelhada), 2 - sementes inviáveis (sem coloração), os resultados foram expressos em porcentagem de sementes viáveis.

O número menor de sementes utilizado nos testes de germinação e tetrazólio, em comparação com o indicado na literatura para a realização desses testes (Brasil, 2009), se deve à pouca quantidade de sementes obtidas para o experimento. No entanto, nesses casos, segundo Pinã-Rodrigues et al. (2004), é possível a redução do número de sementes por repetição.

Para a determinação da integridade do DNA, sementes de ambos os tratamentos foram previamente congeladas em nitrogênio líquido e estocadas em Deep Frezzer (temp. $-70^{\circ} \mathrm{C}$ ) até o momento das análises. As sementes armazenadas com fruto foram extraídas antes de serem congeladas em nitrogênio líquido.

Para as análises, as sementes foram maceradas em nitrogênio líquido, com o auxílio de um moinho elétrico. Foi utilizado o protocolo CTAB (Brasileiro \& Carneiro, 1998) para a extração: 40 a $50 \mathrm{mg}$ das amostras maceradas foram colocadas em microtubos de $2 \mathrm{ml}$, ao qual foram acrescidos $350 \mu \mathrm{L}$ de tampão CTAB contendo $2 \%$ de $\beta$-mercaptoetanol, e incubadas em banho-maria 
a $65^{\circ} \mathrm{C}$ por 1 hora. Foram adicionadas ao microtubo $350 \mu \mathrm{L}$ da solução CIA (clorofórmio-álcool-isoamílico) sendo o conteúdo homogeneizado por 25 minutos. As amostras foram centrifugadas a $1.400 \mathrm{rpm}$ por 10 minutos, o sobrenadante foi transferido para outro microtubo de $2 \mathrm{ml}$, ao qual foram adicionados $250 \mu \mathrm{L}$ de isopropanol, depois colocadas em freezer durante 1 hora para decantação do DNA. As amostras foram novamente centrifugadas, operação na qual se descartou o sobrenadante, e ao precipitado formado foram adicionados etanol 70\% e álcool absoluto (95\%) para lavagem. O precipitado foi suspenso em solução TE pH 8 e armazenado em geladeira até a quantificação em gel agarose $(0,8 \%)$, realizada em cuba de eletroforese com solução TBE $0,5 \times$, corrente elétrica de 100 volts, pelo período de aproximadamente 2 horas.

As amostras foram fotografadas em transluminador, sendo a visualização por UV pela adição de brometo de etídeo no gel. A quantificação de DNA em cada etapa de armazenamento foi realizada em espectrofotômetro NanoDrop ${ }^{\circledR}$ ND-1000.

Os experimentos foram instalados em delineamento inteiramente casualizado (DIC). Os dados foram testados quanto à homogeneidade e normalidade e foi realizada análise de variância. Os dados de germinação e tetrazólio, expressos em porcentagens, que se mostraram não homogêneos pelo teste de Shapiro-Wilk, foram transformados em arco seno $\sqrt{ }^{-} \mathrm{x} / 100$ (Santana \& Ranal, 2004). As médias foram comparadas pelo teste de Tukey a $5 \%$ de probabilidade - as análises foram realizadas com o programa estatístico ASSISTAT ${ }^{\circledR}$.

\section{RESULTADOS E DISCUSSÃO}

$\mathrm{Na}$ análise dos dados foi verificado que a interação tripla (sementes com ou sem fruto $\mathrm{X}$ períodos de armazenamento $\mathrm{X}$ lotes) não foi significativa, sendo observada interação significativa entre lotes X sementes com e sem frutos, tempo de armazenamento $\mathrm{X}$ lotes e tempo de armazenamento $\mathrm{X}$ sementes com e sem frutos, todos $\mathrm{p}<0,05$.

A germinação observada em sementes recém-colhidas variou entre 52\% e 95\% (Tabela 2). As diferenças encontradas na germinação de lotes de procedência distinta da mesma espécie podem ocorrer, conforme Wielewicki et al. (2006), devido à variabilidade genética das espécies florestais silvestres ou, ainda, devido a fatores correlacionados à época de maturação, à colheita e ao beneficiamento de sementes. Diversos fatores internos e externos à semente podem interferir na germinação (Malavasi, 1988; Marcos, 2005).

Foi verificado que sementes armazenadas sem o fruto mantiveram sua germinação por até 6 meses, exceto para o lote 4 , em que foi observada redução na porcentagem de germinação de sementes. Nesse período (6 meses de armazenamento), a germinação das sementes foi reduzindo-se gradativamente, independente da presença ou não do fruto, e aos 9 meses as sementes de todos os lotes não mais germinaram (Tabela 2). A perda da viabilidade, ao longo do tempo, é comum em sementes classificadas como recalcitrantes, como

Tabela 2. Germinação (\%) de sementes de Ocotea puberula, armazenadas com (CF) e sem o fruto (SF), pelos períodos de 0, 3, 6 e 9 meses em câmara fria e seca $\left(40 \% \pm 3 \%\right.$ UR e $\left.10^{\circ} \mathrm{C} \pm 2{ }^{\circ} \mathrm{C}\right)$.

Table 2. Germination (\%) of Ocotea puberula seeds stored with (CF) and without fruit (SF) for a period of 0, 3, 6 and 9 months in cold and dry chamber $\left(40 \% \pm 3 \% \mathrm{RH}\right.$ and $\left.10{ }^{\circ} \mathrm{C} \pm 2{ }^{\circ} \mathrm{C}\right)$.

\begin{tabular}{|c|c|c|c|c|c|c|c|c|}
\hline \multirow{3}{*}{ Lote } & \multirow{3}{*}{0 meses } & \multicolumn{6}{|c|}{ Armazenamento } & \multirow{3}{*}{ CV\% } \\
\hline & & \multicolumn{2}{|c|}{3 meses } & \multicolumn{2}{|c|}{6 meses } & \multicolumn{2}{|c|}{9 meses } & \\
\hline & & SF & CF & SF & $\mathrm{CF}$ & SF & $\mathrm{CF}$ & \\
\hline L1 & $66 \mathrm{Abc}^{\star}$ & $56 \mathrm{ABb}$ & $51 \mathrm{Bb}$ & $14 \mathrm{Cab}$ & $2 \mathrm{Cab}$ & $0 \mathrm{C}$ & $0 \mathrm{C}$ & 27,76 \\
\hline $\mathrm{L} 2$ & $95 \mathrm{Aa}$ & $78 \mathrm{Ba}$ & $76 \mathrm{Ba}$ & $2 \mathrm{Cb}$ & $0 \mathrm{Cb}$ & $0 \mathrm{C}$ & $0 \mathrm{C}$ & 8,99 \\
\hline L3 & $75 \mathrm{Aab}$ & $61 \mathrm{ABab}$ & $42 \mathrm{Bb}$ & $18 \mathrm{Cab}$ & $0 \mathrm{Cb}$ & $0 \mathrm{C}$ & $0 \mathrm{C}$ & 29,32 \\
\hline $\mathrm{L} 4$ & $68 \mathrm{Abc}$ & $58 \mathrm{ABab}$ & $46 \mathrm{Bb}$ & $0 \mathrm{Cb}$ & $8 \mathrm{Ca}$ & $0 \mathrm{C}$ & $0 \mathrm{C}$ & 24,08 \\
\hline L5 & $52 \mathrm{Ac}$ & $44 \mathrm{Ab}$ & $28 \mathrm{Bc}$ & $26 \mathrm{Ba}$ & $0 \mathrm{Cb}$ & $0 \mathrm{C}$ & $0 \mathrm{C}$ & 29,47 \\
\hline CV (\%) & 13,16 & 16,34 & 14,08 & 62,27 & 158,11 & - & - & \\
\hline $\mathrm{F}_{\text {cal }}$ & 11,10 & 6,29 & 26,75 & 8,43 & 4,25 & - & - & \\
\hline
\end{tabular}

* Médias seguidas por mesma letra maiúscula na linha e minúscula na coluna não diferem entre si pelo teste de Tukey ao nível de $5 \%$ de probabilidade. 
Euterpe edulis (Martins et al., 2009) e Eugenia pyriformis (Scalon et al., 2012).

Os resultados relacionados à manutenção dos frutos para o armazenamento das sementes divergem dos obtidos para algumas espécies florestais, como Caesalpinia leiostachya (Biruel et al., 2007) e Crambe abyssinica (Costa et al., 2012), para as quais o armazenamento das sementes com fruto foi eficaz, mantendo a viabilidade por mais tempo em relação às sementes sem fruto. O mesmo comportamento foi verificado por Randi (1982), para sementes de O. puberula. De acordo com esse autor, os frutos possuem substâncias inibidoras da germinação, o que garante a dormência das sementes com fruto durante o armazenamento, possibilitando maior período de viabilidade.

Os resultados do teste de tetrazólio foram semelhantes aos de germinação em relação à melhor manutenção das sementes sem o fruto, exceto para os lotes 2 e 4 . No entanto, de forma geral foi verificada no teste de tetrazólio uma menor redução na viabilidade das sementes até os 6 meses de armazenamento em comparação com os resultados de germinação (Tabela 3 ).

Marcos (2005) e Walters et al. (2005) afirmam que sementes recalcitrantes, ao serem armazenadas, mantêm a taxa de respiração consideravelmente alta e o metabolismo ativo, mas à medida que se aumenta o tempo de armazenamento o sistema de reparo das sementes já não funciona perfeitamente, reduzindo o potencial de germinação.
Pelo presente trabalho, é possível afirmar que, de forma geral, há redução na viabilidade das sementes de Ocotea puberula após 3 meses de armazenamento em ambiente controlado (câmara fria e seca) (Tabela 3), sendo que após 6 meses a viabilidade é nula. Eibl et al. (1994) encontraram comportamento semelhante ao armazenar sementes da mesma espécie em ambiente não controlado, afirmando que as sementes são de comportamento recalcitrante ao armazenamento, perdendo totalmente a viabilidade em ambiente não controlado em três meses, sendo difícil a sua conservação.

Em relação ao teor de água foi verificada grande variação ao longo dos 9 meses de armazenamento, sendo que para todos os lotes houve decréscimo significativo da umidade inicial após armazenamento. Sementes do Lote 1 , por exemplo, que tinham $36,13 \%$ de umidade inicial, após 9 meses de armazenamento reduziram as porcentagens para: $10,24 \%$ em sementes sem o fruto e $8,20 \%$ em sementes com fruto (Tabela 4).

Os resultados observados sugerem que a umidade das sementes foi um fator decisivo para o armazenamento. Acredita-se que devido ao uso de papel kraft e câmara fria e seca, as sementes sofreram secagem durante o armazenamento, reduzindo-se o teor de água, provavelmente, para além do limite letal e ocasionando a morte das sementes. $\mathrm{O}$ grau de umidade letal equivale ao valor a partir da qual todas as sementes perdem a viabilidade (Hong \& Ellis, 1996). Para sementes recalcitrantes, o ideal é o armazenamento em câmaras úmidas.

Tabela 3. Viabilidade (\%) de sementes de Ocotea puberula obtida pelo teste de tetrazólio, armazenadas pelos períodos de 0, 3, 6 e 9 meses, com (CF) e sem o fruto (SF).

Table 3. Viability (\%) of Ocotea puberula seeds, obtained by the tetrazolium test, stored for a period of $0,3,6 \mathrm{e}$ 9 months, with (CF) and without fruit (SF).

\begin{tabular}{|c|c|c|c|c|c|c|c|c|}
\hline \multirow{3}{*}{ Lote } & \multirow{3}{*}{0 meses } & \multicolumn{6}{|c|}{ Armazenamento } & \multirow{3}{*}{ CV\% } \\
\hline & & \multicolumn{2}{|c|}{3 meses } & \multicolumn{2}{|c|}{6 meses } & \multicolumn{2}{|c|}{9 meses } & \\
\hline & & SF & CF & SF & CF & SF & CF & \\
\hline L1 & $74 \mathrm{Aa}^{*}$ & $52 \mathrm{ABab}$ & $18 \mathrm{CDd}$ & $40 \mathrm{BCab}$ & $14 \mathrm{CDc}$ & $0 \mathrm{D}$ & $0 \mathrm{D}$ & 41,62 \\
\hline L2 & $77 \mathrm{Aa}$ & $62 \mathrm{ABab}$ & $70 \mathrm{Aa}$ & $44 \mathrm{Bab}$ & $48 \mathrm{Ba}$ & $0 \mathrm{C}$ & $0 \mathrm{C}$ & 19,36 \\
\hline L3 & $53 \mathrm{Bb}$ & $77 \mathrm{Aa}$ & $33 \mathrm{Ccd}$ & $57 \mathrm{Ba}$ & $24 \mathrm{Cbc}$ & $0 \mathrm{D}$ & $0 \mathrm{D}$ & 23,22 \\
\hline $\mathrm{L} 4$ & $72 \mathrm{Aa}$ & $45 \mathrm{ABCb}$ & $58 \mathrm{ABab}$ & $27 \mathrm{CDb}$ & $44 \mathrm{BCa}$ & $0 \mathrm{D}$ & $0 \mathrm{D}$ & 33,26 \\
\hline L5 & $50 \mathrm{Bb}$ & $65 \mathrm{Aab}$ & $45 \mathrm{BCbc}$ & $48 \mathrm{Bab}$ & $33 \mathrm{Cbc}$ & $0 \mathrm{D}$ & $0 \mathrm{D}$ & 15,19 \\
\hline CV (\%) & 13,62 & 23,66 & 21,46 & 26,84 & 31,07 & - & - & \\
\hline $\mathrm{F}^{\mathrm{cal}}$ & 7,74 & 3,01 & 17,84 & 3,72 & 7,78 & - & - & \\
\hline
\end{tabular}

* Médias seguidas por mesma letra maiúscula na linha e minúscula na coluna não diferem entre si pelo teste de Tukey ao nível de $5 \%$ de probabilidade. 
$\mathrm{Na}$ análise das sementes foi possível visualizar a degradação da integridade do DNA ao longo do armazenamento. Por exemplo, o DNA de sementes do Lote 1 (Figura 1), no tempo zero de armazenamento, encontrava-se íntegro, com pouco arraste vertical. Com 3 meses de armazenamento, o DNA se encontrava menos integro, com uma concentração de arraste maior na proporção mediana do gel de agarose. Com 6 meses de armazenamento, o DNA tinha uma pequena proporção íntegra (acumulada no início do gel) e arraste ao longo do gel de agarose; no armazenamento de 9 meses houve uma quantidade ainda menor de DNA íntegro e arraste ao longo do gel de agarose. O mesmo padrão pôde ser observado nos demais lotes (Figura 1 Gráfico 1).

Células vegetais, quando sujeitas a estresses ambientais, possuem um padrão de degradação relacionado ao processo de morte celular passiva (Wang et al., 1998). A temperatura e a umidade relativa do ar do local em

Tabela 4. Teor de água (\%) das sementes de Ocotea puberula armazenadas em câmara fria e seca pelo período 0, 3, 6 e 9 meses, com (CF) e sem o fruto (SF).

Table 4. Water content (\%) of seeds of Ocotea puberula stored in cold and dry chamber for a period of 0, 3, 6 and 9 months, with (CF) and without fruit (SF).

\begin{tabular}{|c|c|c|c|c|c|c|c|c|}
\hline \multirow{3}{*}{ Lote } & \multirow{3}{*}{0 meses } & \multicolumn{6}{|c|}{ Armazenamento } & \multirow{3}{*}{ CV\% } \\
\hline & & \multicolumn{2}{|c|}{3 meses } & \multicolumn{2}{|c|}{6 meses } & \multicolumn{2}{|c|}{9 meses } & \\
\hline & & SF & CF & SF & $\mathrm{CF}$ & SF & CF & \\
\hline L1 & $36,13 \mathrm{Ab}^{*}$ & $17,13 \mathrm{Bc}$ & $14,34 \mathrm{BCb}$ & $11,67 \mathrm{CDb}$ & $10,24 \mathrm{CDb}$ & $10,24 \mathrm{CDb}$ & $8,20 \mathrm{Da}$ & 4,62 \\
\hline $\mathrm{L} 2$ & $35,62 \mathrm{Ab}$ & $26,88 \mathrm{Ba}$ & $22,82 \mathrm{BCa}$ & $21,46 \mathrm{BCa}$ & $13,21 \mathrm{CDa}$ & $13,21 \mathrm{CDa}$ & $8,13 \mathrm{Da}$ & 8,69 \\
\hline L3 & $40,34 \mathrm{Aa}$ & $22,13 \mathrm{Bb}$ & $16,36 \mathrm{Cab}$ & $12,84 \mathrm{Dab}$ & $10,32 \mathrm{~Eb}$ & $10,32 \mathrm{~Eb}$ & 7,40 Fa & 2,73 \\
\hline L4 & $38,85 \mathrm{Aa}$ & $20,81 \mathrm{Bbc}$ & $19,94 \mathrm{Bab}$ & $16,91 \mathrm{BCab}$ & $11,70 \mathrm{CDab}$ & $11,70 \mathrm{CDab}$ & $8,05 \mathrm{Da}$ & 5,41 \\
\hline L5 & $40,94 \mathrm{Aa}$ & $27,05 \mathrm{Ba}$ & $22,72 \mathrm{Ba}$ & $19,10 \mathrm{Bab}$ & 11,46 CDab & $11,46 \mathrm{CDab}$ & $9,22 \mathrm{Da}$ & 6,2 \\
\hline CV (\%) & 1,53 & 4,38 & 10,65 & 13,79 & 3,89 & 3,89 & 5,87 & \\
\hline $\mathrm{F}^{\mathrm{cal}}$ & 33,63 & 35,69 & 6,76 & 6,66 & 15,05 & 15,05 & 3,67 & \\
\hline
\end{tabular}

${ }^{*}$ Médias seguidas por mesma letra maiúscula na linha e minúscula na coluna não diferem entre si pelo teste de Tukey ao nível de 5\% de probabilidade.

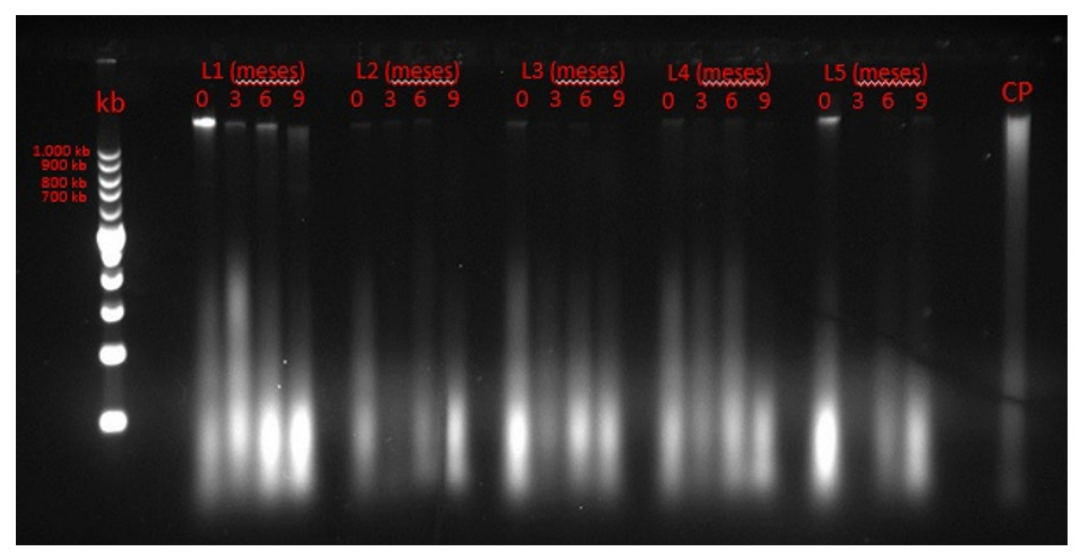

$\mathrm{kb}=$ pares de base $; \mathrm{L} 1=$ Lote $1 ; \mathrm{L} 2=$ Lote $2 ; \mathrm{L} 3=$ Lote $3 ; \mathrm{L} 4=$ Lote $4 ; \mathrm{L} 5=$ Lote $5 ; \mathrm{CP}=$ Controle positivo

- amostra com DNA conhecido

Figura 1. Gel de agarose $(0,8 \%)$ de DNAs genômicos extraídos de sementes de Ocotea puberula, ao longo do armazenamento por 0, 3, 6 e 9 meses, em câmara fria e seca.

Figure 1. Agarose gel $(0,8 \%)$ of genomic DNA extracted from seeds of Ocotea puberula, during storage for $0,3,6$ and 9 months in cold and dry chamber. 


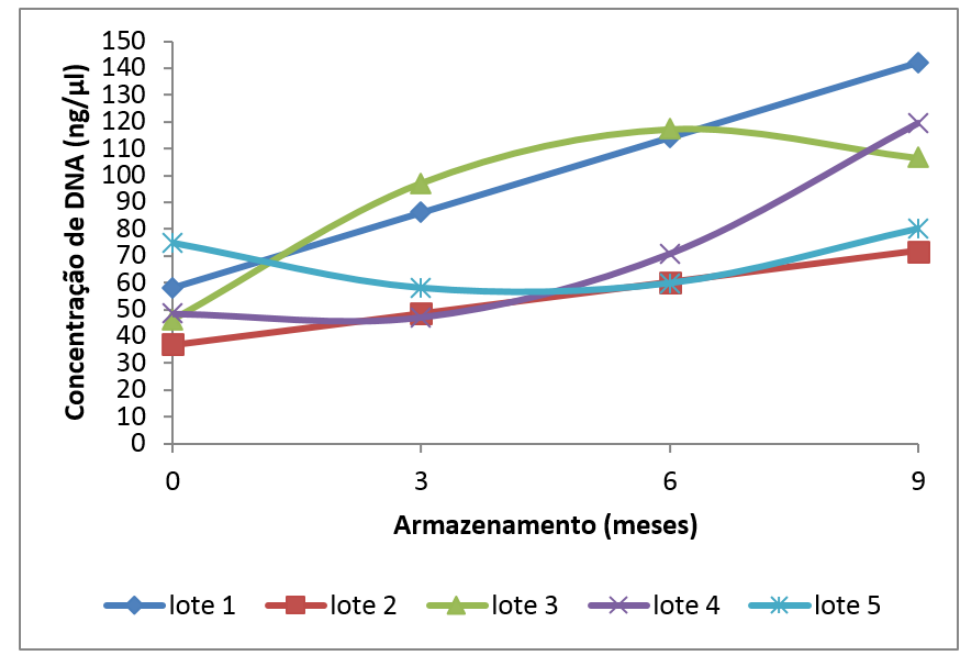

Lote 1: $y=58,25+9,32 x\left(R^{2}=0,999\right) ;$ Lote $2: y=36,99+3,88 x\left(R^{2}=0,999\right) ;$ Lote $3: y=61,74+6,70 x\left(R^{2}\right.$

$=0,680) ;$ Lote $4: \mathrm{y}=35,96+7,88 \mathrm{x}\left(\mathrm{R}^{2}=0,817\right) ;$ Lote $5: \mathrm{y}=43,78+3,72 \mathrm{x}\left(\mathrm{R}^{2}=0,810\right)$

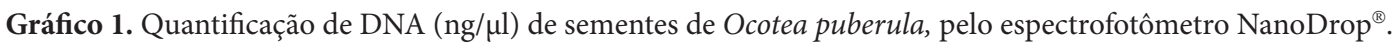
Graphic 1. Quantification of DNA (ng/ $\mu \mathrm{L})$ Ocotea puberula seeds by NanoDrop ${ }^{\circledR}$ spectrophotometer.

que as sementes são armazenadas são os principais fatores a afetar a sua qualidade fisiológica. Tais danos acumulam-se mais rapidamente em sementes úmidas que nas secas e estão relacionados ao envelhecimento e à perda da viabilidade das sementes (Marcos, 2005).

A manutenção da informação genética é um requisito essencial para a tolerância à dessecação e a sobrevivência das células (Osborne et al., 2002). Pelos resultados obtidos, podemos inferir que em sementes armazenadas de Ocotea puberula a degradação do DNA ocorre nos estágios iniciais do processo de deterioração.

\section{CONCLUSÕES}

Sementes de Ocotea puberula, com ou sem fruto, armazenadas em sacos de papel kraft reduzem sua viabilidade e integridade de DNA após 3 meses de armazenamento em câmara fria e seca a $40 \% \pm 3 \%$ de UR e $10{ }^{\circ} \mathrm{C} \pm 2{ }^{\circ} \mathrm{C}$.

\section{STATUS DA SUBMISSÃO}

Recebido: 4 ago., 2014

Aceito: 15 mar., 2016

\section{AUTOR(ES) PARA CORRESPONDÊNCIA}

\section{Dalciana Vicente}

Departamento de Engenharia Florestal, Universidade do Estado de Santa Catarina UDESC, Avenida Luiz de Camões, 2090, Conta Dinheiro, CEP 88520-000, Lages, SC, Brasil e-mail:dalciana@gmail.com

\section{REFERENNCIAS}

Bilia DAC, Barbedo CJ, Maluf AM. Germinação de diásporos de Canela (Ocotea corymbosa) Meissn. Mez LAURACEAE) em função da temperatura, do substrato e da dormência. Revista Brasileira de Sementes 1998; 20(1): 189-194. http://dx.doi.org/10.17801/0101-3122/ rbs.v20n1p189-194.

Biruel RP, Aguiar IB, Paula RC. Germinação de sementes de pau-ferro submetidas a diferentes condições de armazenamento, escarificação química, temperatura e luz. Revista Brasileira de Sementes 2007; 29(3): 151-159. http://dx.doi.org/10.1590/S0101-31222007000300018.

Brasil. Ministério da Agricultura e Reforma Agrária. Regras para análise de sementes. Brasília: 2009. 365 p.

Brasileiro ACM, Carneiro VTC. Manual de transformação genética de plantas. Brasília: EMBRAPA-SPI; 1998. 309 p. 
Carvalho LR, Davide AC, Silva EAA, Carvalho MLM. Classificação de sementes de espécies florestais dos gêneros Nectandra e Ocotea (Lauraceae) quanto ao comportamento no armazenamento. Revista Brasileira de Sementes 2008; 30(1): 1-9. http://dx.doi.org/10.1590/ S0101-31222008000100001.

Carvalho NM, Nakagawa J. Sementes: ciência, tecnologia e produção. Jaboticabal: FUNEP; 2012.590 p.

Costa LM, Resende O, Gonçalves DN, Souza KA. Qualidade dos frutos de crambe durante o armazenamento. Revista Brasileira de Sementes 2012; 34(2): 239-301. http://dx.doi. org/10.1590/S0101-31222012000200015.

Eibl BI, Silva F, Carvalho A, Czerepak R, Kehl J. Ensayos de germinación y análisis cuantitativo en semillas de especies forestales nativas de Misiones, R.A Yvyraretá. Eldorado 1994; 5(5): 33-48.

Floriano EP. Armazenamento de sementes florestais. Santa Rosa: ANORGS; 2014. 10 p. Caderno Didático.

Hong TD, Ellis RH. A protocol to determine seed storage behavior. Rome: IPGRI; 1996. $62 \mathrm{p}$.

Kalil AN Fo, Lopes AJ, Rêgo GM, Tomachitz A. Avaliação da qualidade fisiológica de sementes de imbuia pelo teste do tetrazólio: nota científica. Pesquisa Florestal Brasileira 2008; 57: 69-72.

Köppen W, Geiger R, editors. Handbuch der klimatologie. Berlin: Gebruder Borntraeger; 1936. vol. 1, p. 1-44.

Malavasi MM. Germinação de sementes. In: PiñaRodrigues FCM, coordenador. Manual de análise de sementes florestais. Campinas: Fundação Cargil; 1988. p. 25-40.

Marcos J Fo. Fisiologia de sementes de plantas cultivadas. Piracicaba: FEALQ; 2005. 495 p.

Martins CC, Bovi MLA, Nakagawa J, Machado CG. Secagem e armazenamento de sementes de juçara. Revista Árvore 2009; 33(4): 635-642. http://dx.doi.org/10.1590/ S0100-67622009000400006.

Mello JI. O. Compostos de reserva de sementes e suas relações com diferentes niveis de sensibilidade à dessecação e ao congelamento [dissertação]. São Paulo: Instituto de Botânica da Secretaria do Meio Ambiente; 2008.

Montagnini F, Eibl B, Fernández R. Rehabilitation of degraded lands in Missiones, Argentina. Bois et Forêts des Tropiques 2006; 288(2): 51-65.

Montrucchio DP, Miguel OG, Zanin SMW, Silva GA, Cardozo AM, Santos ARS. Antinociceptive effects of a chloroform extract and the alkaloid dicentrine isolated from fruits of Ocotea puberula. Planta Medica 2012; 78(14): 1543-1548. http://dx.doi.org/10.1055/s-0032-1315026. PMid:22815198.

Mori ES, Pinã-Rodrigues FCM, Freitas NP, Martins RB, organizadores. Sementes florestais: guia para germinação de 100 espécies nativas. São Paulo: Instituto Refloresta; 2012. $159 \mathrm{p}$.

Moritz A, Degenhardt J, Dutra LF, Hansel FA, Lima $\mathrm{BH}$, Franceschi $\mathrm{CRB}$ et al. Estabelecimento in vitro de Ocotea odorifera, O. catharinensis e O. porosa. Pesquisa Florestal Brasileira 2009; 59: 37-44.

Osborne DJ, Boubriak I, Leprince O. Rehydration of dried systems: membranes and nuclear genome. In: Black M, Pritchard HW, editores. Desiccation and survival in plants: drying without dying. Wallingford: CABI Publishing; 2002. p. 343-364.

Pinã-Rodrigues FCM, Figliolia MB, Peixoto MC. Testes de qualidade. In: Ferreira AG, Borghetti F. Germinação: do básico ao aplicado. Porto Alegre: Artmed; 2004. p. 283-297.

Randi AM. Estudo preliminar sobre inibidores de germinação em frutos de Miconia cinnamomifolia e Ocotea puberula. In: Anais do Congresso nacional sobre essências nativas; 1982; Campos do Jordão. São Paulo: Instituto Florestal; 1982. p. 238-242.

Santa Catarina. Governo do Estado. 2014. [citado em 2014 jan. 16]. Disponível em: http://www.sc.gov.br

Santana DG, Ranal MA. Análise da germinação: um enfoque estatístico. Brasília: Editora Universidade de Brasília; 2004. 248 p.

Santos HP, Tine MA, Aidar MPM. Mobilização de reservas. In: Ferreira AG, Borgheti F, editores. Germinação: do básico ao aplicado. Porto Alegre: Artmed; 2004. p. 163-185.

Scalon SPQ, Neves SEM, Maseto TE, Pereira ZV. Sensibilidade à dessecação e ao armazenamento em sementes de Eugenia pyriformis Cambess. (uvaia). Revista Brasileira de Fruticultura 2012; 34(1): 269-276. http://dx.doi.org/10.1590/S0100-29452012000100036.

Silva KB, Alves EU, Bruno RLA, Santos SS, Barroso LM. Tolerância à dessecação de sementes de Cinnamomum zeylanicum Ness. Semina: Ciências Agrárias 2012; 33(2): 587-594.

Tekrony DM, Egli DB, White GM. Seed production and technology. In: Wilcox JR, editor. Soybeans: improvement, production and uses 1. Madison: American Society of Agronomy; 1987. p. 295-353.

Vicente D. Dormência, secagem, armazenamento e sanidade de sementes de Ocotea puberula (Rich.) Nees [dissertação]. Lages: Universidade do Estado de Santa Catarina; 2014. 56 p.

Walters C, Hill LM, Wheeler LJ. Dying while dry: kinetics and mechanisms of deterioration in desiccated organisms. Integrative and Comparative Biology 2005; 45(5): 751-758. http://dx.doi.org/10.1093/icb/45.5.751. PMid:21676826. 
Wang DG, Fan J-B, Siao CJ, Berno A, Young P, Sapolsky $\mathrm{R}$ et al. Large-scale identification, mapping, and genotyping of single-nucleotide polymorphisms in the human genome. Science 1998; 280(5366): 1077-1082. http:// dx.doi.org/10.1126/science.280.5366.1077. PMid:9582121.

Wielewicki AP, Leonhardt C, Schlindwein G, Medeiros ACS. Proposta de padrões de germinação e teor de água para sementes de algumas espécies florestais presentes na região sul do Brasil. Revista Brasileira de Sementes 2006; 28(3): 191-197. http://dx.doi.org/10.1590/S010131222006000300027.

Zangaro W, Nisizaki SMA, Domingos JCB, Nakano EM. Mycorrizhal response and sucessional status in 80 woody species from south Brazil. Journal of Tropical Ecology 2003; 19(3): 315-324. http://dx.doi.org/10.1017/ S0266467403003341. 